\title{
Correlation between nematode abundance and decomposition rate of Spartina anglica leaves
}

\author{
R. Alkemade*, A. Wielemaker, M. A. Hemminga \\ Netherlands Institute of Ecology - Centre for Estuarine and Coastal Ecology, Vierstraat 28, 4401 EA Yerseke, The Netherlands
}

\begin{abstract}
Dead Spartina anglica leaves which are not washed away by the tides either decompose in the canopy as standing dead crop or decompose on the sediment surface. In the sediment, many nematode species are present which may colonize the Spartina litter. Some of these species may affect the decomposition of Spartina detritus. A field experiment was carried out to identify these nematode species. Small mesh containers were filled with green or aged Spartina leaves to obtain different decomposition rates. The containers were placed in the Stroodorpepolder salt marsh (The Netherlands), in the Oosterschelde, a tidal inlet of the southern North Sea. After 3 mo the containers were collected and nematodes were counted and identified. The experiment was repeated in 4 subsequent seasons. Sixty nematode species were found in the containers; most species were found in all treatments. Total numbers of nematodes did not differ among treatments. Using multivariate analysis (RDA), however, we found differences of nematode community structure among treatments. Bacterivorous nematodes, particularly monhysterid species, prevailed in the containers with the highest decomposition rates. A positive correlation was found between decomposition rate and the numbers of Diplolaimella dievengatensis in spring, summer and autumn. The numbers of Diplolaimelloides bruciei, Monhystera parva, Desmolaimus zeelandicus and Theristus acer showed positive correlations with decomposition rates in 1 or 2 of these seasons. In winter no significant correlations were found. Thus, of the 60 nematode species present in the litter the abundances of only 5 species seemed to be affected by decomposition rate of the litter. It is suggested that these nematode species react primarily to the increased microbial activity coinciding with higher decomposition rates. In addition, these species may further enhance microbial decomposition activity.
\end{abstract}

\section{INTRODUCTION}

Spartina anglica is a common halophyte of the lower zones of Western European salt marshes. Dead aboveground material of $S$. anglica which is not removed by the tides either decomposes in the canopy or on the sediment surface. Recent studies on the decomposition of Spartina material on the sediment surface showed that litter-associated nematodes are always found in high numbers (Montagna \& Ruber 1980, Reice \& Stiven 1983, Buth \& de Wolf 1985, Hemminga \& Buth 1991). A correlation between total nematode densities and decomposition rates, however, could not be established

\footnotetext{
- Present address: National Institute for Public Health and Environmental Protection, Laboratory LBG, PO Box 1, 3720 BA Bilthoven, The Netherlands
}

(Reice \& Stiven 1983, Buth \& de Wolf 1985). In these studies nematodes were considered as 1 taxon, which masks possible differences among individual species with respect to their dependence on, or their role in, litter decomposition. The number of specimens of those species that feed on microbial decomposers is presumably determined by the decomposition rate, as at higher decomposition rates the microbial production will probably be higher, thus providing more food to microbial grazers.

In the present study, experiments were carried out to investigate changes in the nematode community in relation to changing decomposition rates of Spartina anglica leaf litter. An attempt was made to detect those nematode species, whose numbers correlated with decomposition rate.

Differences in decomposition rates were obtained by using leaf litter of different ages. Decomposition rate 
decreases during decomposition: the readily available substances, such as proteins and sugars, are lost first from the litter, leaving the more refractory components which decompose at much lower rates. Nematode densities are subject to conspicuous seasonal fluctuations (Buth \& de Wolf 1985, Heip et al. 1985, Vincx 1989). Some species are found only in certain seasons. The experiments, therefore, were repeated in all 4 seasons.

Redundancy analysis (RDA) was used to evaluate the relation between nematode community structure and decomposition rates.

\section{MATERIAL AND METHODS}

Leaf material. Green leaves of Spartina anglica were collected in the Stroodorpepolder salt marsh (The Netherlands) in January 1988. This marsh is situated in the Oosterschelde, a tidal inlet of the southern North Sea. Immediately after harvesting, the leaves were washed and cut into fragments of $2 \mathrm{~cm}$. To obtain leaf litter of progressive decomposition stages, the material was split into 3 portions. One part was immediately dried at $50^{\circ} \mathrm{C}(48 \mathrm{~h})$ and stored. The other portions were aged for 2.5 and 5 mo by putting the leaf fragments into a bag of nylon gauze ( $2 \mathrm{~mm}$ mesh) and, in the laboratory, placing them in a tank on sediment originating from the Stroodorpepolder salt marsh. The sediment was flooded each day $(3 \mathrm{~h})$ with water from the Oosterschelde. The ambient temperature ranged from 15 to $25^{\circ} \mathrm{C}$; the temperature of the flooding water ranged from 15 to $20^{\circ} \mathrm{C}$. After 2.5 and 5 mo part of the leaf material was removed and dried at $50^{\circ} \mathrm{C}$ for $48 \mathrm{~h}$. A sample of leaf material was used for determining the initial contents of carbon, nitrogen and phosphate

Experimental design. Mesh containers were filled with $5 \mathrm{~g}$ dry weight (DW) of 1 of the 3 types of plant material. In addition, inert fragmented plastic drinking straws were used in control treatments. The containers used were permeable, consisting of $2 \mathrm{~cm}$ segments of perspex cylinders with a diameter of $7 \mathrm{~cm}$, closed at both ends with $0.8 \mathrm{~mm}$ mesh gauze.

Four subsequent experiments were conducted at the same site in the Stroodorpepolder salt marsh. The site $\left(10 \mathrm{~m}^{2}\right)$ was situated near the edge of the marsh, where Spartina anglica forms a monospecific stand. In each experiment the mesh containers were laid out in 5 randomized blocks, each block in a row parallel to the marsh edge. Within the rows 1 container of each treatment was placed in random order on the sediment surface. The distance between the rows and between the containers within a row was $0.5 \mathrm{~m}$. The containers were anchored by 2 wire wickets to the marsh sediment to prevent them from being washed away at high tide. The experiments started on 15 March, 20 June,
19 September and 20 December 1988. On these dates sediment samples were also collected to compare the number of nematodes in the upper sediment layer with the number found in the containers. The field exposure time of the containers was 3 mo. Containers with $5 \mathrm{mo}$ aged leaves were included only in the summer, autumn and winter experiments.

Decomposition rate and chemical analyses. After retrieval of the mesh containers a small sample of the detritus was washed with tap water and dried for chemical analysis. The remaining part of the detritus was fixed with warm formalin at a final concentration of 4 to $5 \%$. After at least $7 \mathrm{~d}$ the detritus was rinsed with tap water over a household sieve (mesh 1.5 to $2 \mathrm{~mm}$ ) to separate the leaf material from the sediment and nematodes. The leaf material was retained on the sieve, whereas nematodes and sediment passed through. The leaf material was dried and weighed.

Decomposition rates were calculated as the loss of dry weight of leaf material from the mesh containers and expressed as g weight loss per $100 \mathrm{~d}$, using a negative exponential relation for extrapolation (cf. Swift et al. 1979). Carbon and nitrogen content of the samples were analyzed with a Carlo Erba $\mathrm{CN}$-analyzer, type 1500 A. Phosphate content was determined colorimetrically.

Nematodes. Nematodes were extracted using an Oostenbrink elutriator (Fricke 1979, 's Jacob \& van Bezooijen 1986). The nematodes were recovered by passing the suspension with nematodes (see above) through a series of four $45 \mu \mathrm{m}$ mesh sieves. The debris retained on the sieves was collected in $250 \mathrm{ml}$ centrifugation tubes with tap water. After centrifugation ( 5 min at $3000 \mathrm{rpm})(1800 \times g)$ the supernatant was discarded and the nematodes in the pellet were extracted by 2 repeated centrifugation steps (1 min at $3000 \mathrm{rpm}$ ) $(1800 \times g)$ with $\mathrm{a} \mathrm{MgSO}_{4}$ solution (specific gravity 1.28).

Nematodes were counted and 250 individuals were identified to species level using an inverted microscope.

Statistical analysis. Seasonal and treatment differences of losses of weight, nitrogen, carbon and phosphate and the total numbers of nematodes were evaluated using analysis of variance. Redundancy analysis (RDA) was used to evaluate the relation between the nematode community structure and the decomposition rate of the leaf material. RDA is the canonical form of principal component analysis (Jongman et al. 1987). Linearity between environmental gradients and species abundances is assumed for RDA. Since the experiments were carried out on a limited surface area, the environmental gradients were expected to be small. If gradients are small, the assumption for linearity is not very stringent (ter Braak \& Prentice 1988, van der Meer 1990). A $\log (x+1)$ transformation was used in 
order to stabilize variances. The log transformation implies that the assumption of linearity between environmental variables and species abundances must hold for the linearity between the variables and lognumbers. Decomposition rate was included as the only independent variable. Corrections for seasonal effects and effects which may arise from the row-position of the mesh container in the field were made by taking them as covariables in the computer program CANOCO (ter Braak 1990). The result of the RDA then only describes the variation explained by decomposition rate and the variation due to error terms. A Monte Carlo permutation test was carried out to test the significance of decomposition rate as the explaining variable. The species found to be correlated with decomposition rate were analyzed in more detail by regression of the numbers per individual species on the decomposition rate.

ANOVA and regression analyses were carried out with SYSTAT statistical package (Wilkinson 1990). RDA and the Monte Carlo permutation test were carried out with CANOCO 3.10 (ter Braak 1990).

\section{RESULTS}

After a few weeks of exposure in the field the leaf fragments were covered with a layer of sediment in most of the containers. Since the Spartina vegetation was flooded frequently during the course of the experiments, no desiccation of the sediment surface took place.

\section{Decomposition rates}

The decomposition rates of the 3 detrital types in the successive seasons are shown in Fig. 1. Statistically significant treatment and seasonal differences were observed ( $p<0.001$ ). In all seasons decomposition rates of fresh leaves were higher than those of the aged material (Tukey test; $p<0.05$ ). The 2.5 mo aged leaves decomposed slightly faster than the 5 mo aged material, but only in summer was this difference significant (Tukey test; $\mathrm{p}<0.05$ ). The differences between the detrital types were most pronounced in the summer season. The decomposition rates of the fresh leaves showed the most conspicuous seasonal fluctuations, with the highest rates in summer and the lowest in winter.

With respect to the fresh leaf material and to the 2.5 mo aged material, differences in decomposition rates between the various seasons were nearly all significant (Tukey test; $p<0.05$ ). Decomposition rates of the 5 mo aged material were not significantly different

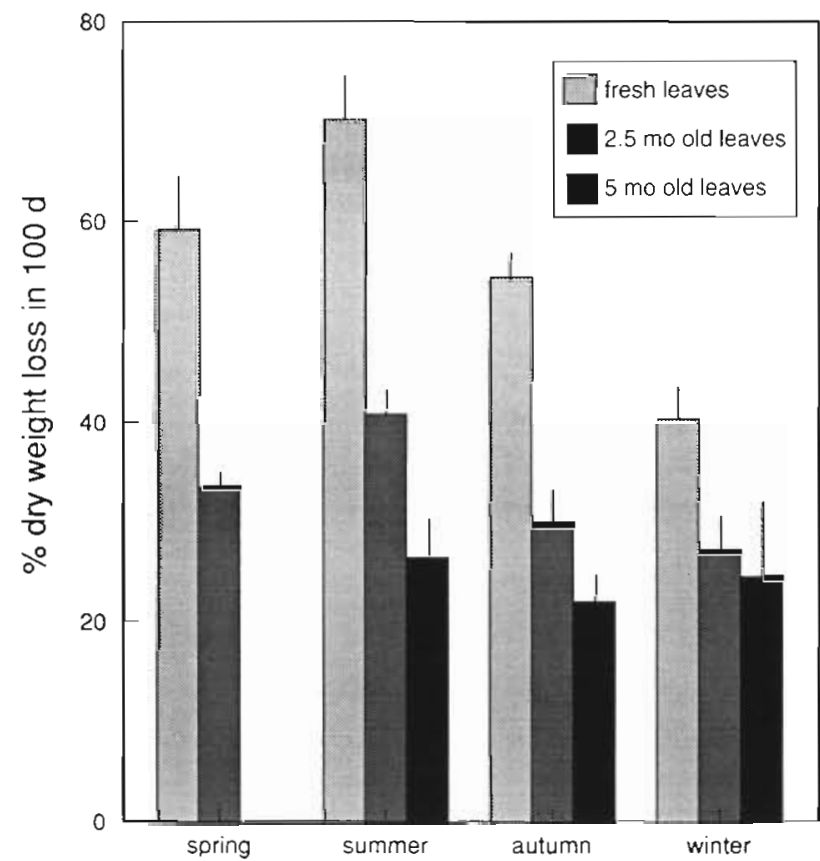

Fig. 1. Spartina anglica. Decomposition rates (\% losses of dry weights of litter after $100 \mathrm{~d})$. Means $+\operatorname{SD}(n=5)$

Table 1. Correlation coefficients between decomposition rates and nutrient losses; all coefficients are significant (Bonferroni $\mathrm{p}<0.001)$

\begin{tabular}{|lccc|}
\hline & $\begin{array}{c}\text { Decompostion } \\
\text { rate }\end{array}$ & Carbon & Nitrogen \\
\hline Carbon & 0.986 & & \\
Nitrogen & 0.930 & 0.943 & \\
Phosphate & 0.923 & 0.939 & 0.925 \\
\hline
\end{tabular}

between seasons. No weight losses from the inert material were observed.

Carbon, nitrogen and phosphate losses yielded similar patterns, the losses of these nutrients were highly correlated with dry weight losses (Bonferroni $p<$ 0.001; Table 1). Carbon, nitrogen and phosphate losses were highest in summer and lowest in winter. The losses of these nutrients were highest from fresh leaf material.

\section{Nematodes}

The total number of nematodes found in the mesh containers showed clear seasonal fluctuations (Table 2). The highest numbers were found in summer, whereas the lowest numbers were present in autumn. The numbers found in the mesh containers were in the 
Table 2. Total number of nematodes found in the mesh containers in the various treatments and seasons and in the same volume of surrounding sediment. -: not sampled

\begin{tabular}{|lrrrrr|}
\hline & Fresh & 2.5 mo old & 6 mo old & Control & Sediment \\
\hline Spring & 22700 & 12700 & - & 14200 & 19400 \\
Summer & 46900 & 34900 & 27800 & 41300 & 28700 \\
Autumn & 9900 & 9400 & 9200 & 9500 & 20300 \\
Winter & 21200 & 13100 & 15300 & 18200 & 11300 \\
\hline
\end{tabular}

very small buccal cavity, are represented by the Halalaimus species and by Oxystomina sp.

RDA analysis was carried out on the whole species assemblage. The relation between the log number of the most dominant species and the decomposition rate showed a linear pattern, therefore we could use and interpret RDA without restriction. Fig. 2A, B shows the RDA ordination diagrams obtained for the mesh

same range as the numbers found in the upper layer of the surrounding sediment. No statistical differences were found between the treatments. Sixty nematode species were found in the mesh containers (Table 3). Most species are known from intertidal estuaries of the southern North Sea (Bouwman 1983, Vincx 1986). The majority of these species are known to feed on a variety of food sources. Carnivorous and omnivorous species are represented by Enoplus communis and Adoncholaimus fuscus. Herbivores are represented by members of the family Chromadoridae. Bacterivorous species are represented by some members of the family Monhysteridae. Selective deposit feeders, with a containers and for the species respectively. The arrows indicate the direction of increasing decomposition rates. The first ordination axis, explained by the decomposition rate, accounted for $6.9 \%$ of the total variance. The Monte Carlo permutation test showed that, in spite of this small percentage of explained variance, the nematode community changed significantly with changing decomposition rate $(F$-ratio $=5.08, p<0.01$ )

In Fig. 2A the different treatments were ordered along the first axis in such a way that the control treatments appear on the left hand side and the fresh leaf treatments appear on the right hand side. In Fig. 2B the ordination diagram of the species is shown. The posi-

Table 3. Species of nematodes found in the litter containers, with abbreviations as used in Fig. 2B

\begin{tabular}{|c|c|c|c|}
\hline Species & Abbreviation & Species & Abbreviation \\
\hline Enoplus communis & Enop comm & Metochromadora vivipara & Meta vivi \\
\hline Anoplostoma viviparum & Anop vivi & Microlaimus globiceps & Micr glob \\
\hline Anticoma acuminata & Anti acum & Microlaimus sp. & Micr sp \\
\hline Dolicholaimus marionj & Doli mari & Nudora bipapillata & Nudo bipa \\
\hline Halalaimus gracilis & Hala grac & Monoposthia costata & Mono cost \\
\hline Halalaimus longicaudatus & Hala long & Leptolaimus mixtus & Lept mixt \\
\hline Oxystomina elongata & Oxys elon & Leptolaimus sp. & Lept sp \\
\hline Adoncholaimus fuscus & Adon fusc & Aegialoalaimus sp. & Aegi sp \\
\hline Viscosia viscosa & Visc visc & Quadricoma scanica & Quad scan \\
\hline Calyptronema maxweberi & Caly maxw & Diplolaimella dievengatensis & Dipl diev \\
\hline Bathylaimus australis & Bath aust & Diplolaimelloides bruciei & Dipl bruc \\
\hline Tripyloides marinus & Trip mari & Monhystera disjuncta & Monh disj \\
\hline Atrochromadora microlaima & Atro micr & Monhystera parva & Monh parv \\
\hline Chromadora nudicapitata & Chro nudi & Monhysterasp. & Monh sp \\
\hline Chromadorina sp. & $\begin{array}{l}\text { Chro ina } \\
\text { Chro ita }\end{array}$ & Daptonerna sp. 1 & Dapt sp1 \\
\hline $\begin{array}{l}\text { Chromadorita sp. } \\
\text { Dichromadora geophila }\end{array}$ & $\begin{array}{l}\text { Cnro lta } \\
\text { Dich geop }\end{array}$ & Daptonema sp. 2 & Dapt sp2 \\
\hline $\begin{array}{l}\text { Dichromadora geophila } \\
\text { Dichromadora scandula }\end{array}$ & Dich scan & Daptonema sp. 3 & Dapt sp3 \\
\hline $\begin{array}{l}\text { Dichromadora scandula } \\
\text { Hypodontolaimus inaequalis }\end{array}$ & Hypo inae & Daptonema sp. 4 & Dapt sp4 \\
\hline Hypodontolaimus sp. & Hypo sp & Daptonema sp. 5 & Dapt sp5 \\
\hline Neochromadora sp. & Neoc sp & Theristus acer & Ther acer \\
\hline Neochromadora poecilosoma & Neoc poec & Theristus pertenuis & Ther pert \\
\hline Prochromadorella paramucrodonta & Proc para & Trichotheristus sp. & Tric sp \\
\hline Ptycholaimellus ponticus & Ptyc pont & Sphaerolaimus sp. & Spha sp \\
\hline Spilophorella paradoxa & Spil para & Desmolaimus zeelandicus & Desm zeel \\
\hline Paracantonchus caecus & Para caec & Metalinhomoeus biformis & Meta bifo \\
\hline Praeacantonchus sp. & Prae sp & Paralinhomoeus sp. & Para linh \\
\hline Sabatieria sp. & Saba sp & Ascolaimus sp. & Ascosp \\
\hline Desmodora communis & Desm comm & Axonolaimus typicus & Axon typi \\
\hline Metochromadora remanei & Meta rema & Pellioditis marina & Pell mari \\
\hline
\end{tabular}


A

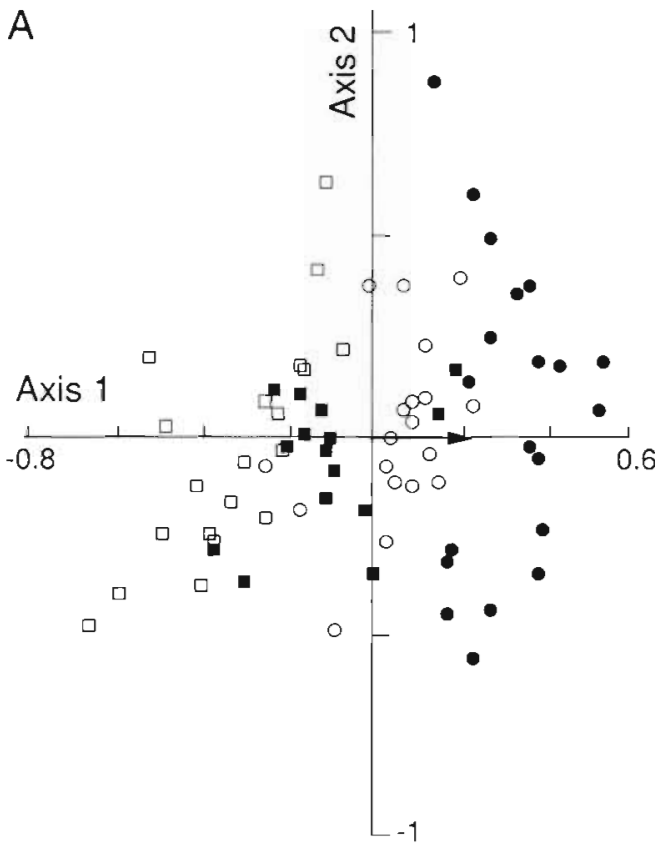

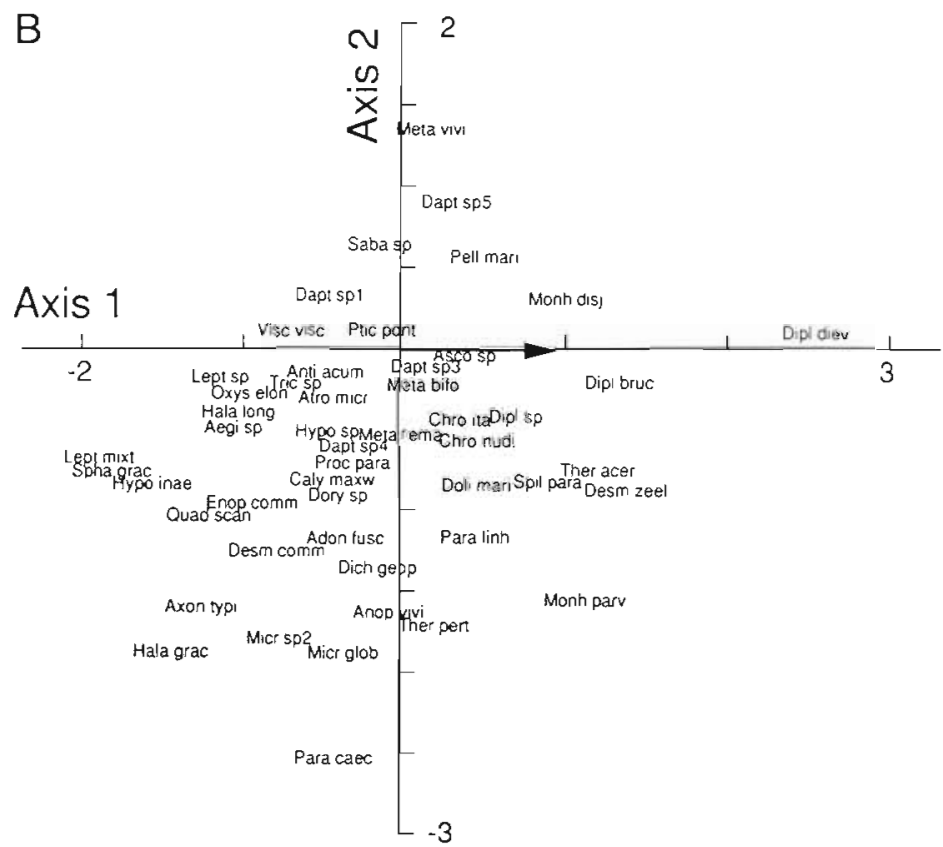

Fig. 2. Ordination diagrams of RDA analysis on nematode abundances in mesh containers. Arrowhead indicates direction of

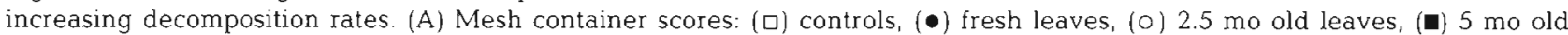
leaves. (B) Species scores. Species as in Table 3

tion of a species in the figure reflects the contribution of the species to the variance explained by the first 2 axes. The species occurring at the left hand side of Fig. 2B are negatively correlated with decomposition rate and species appearing at the right hand side are positively correlated with decomposition rate. So the number of specimens of the majority of the species is not correlated with decomposition rates, as they appear near the origin. The species Leptolaimus mixtus, Sphaerolaimus sp. and Hypodontolaimus inaequalis have high negative scores on the first axis; these species may avoid places with high organic inputs and are found more abundantly in the control treatments. The species Diplolaimella dievengatensis is separated from all other species and has the highest positive scores on the first axis. Other species with high positive scores on the first axis are, in decreasing order, Desmolaimus zeelandicus, Diplolaimelloides bruciei, Theristus acer and Monhystera parva. Thus, the numbers of only these species are positively correlated with decomposition rates. These 5 species are examined in more detail. Fig. 3 shows the relation between the log number of individuals of the 5 species and the weight loss of Spartina anglica leaves from the mesh containers. The regression lines were fitted for each separate season. All data, including zero observations, were used in these analyses. The slopes of the regression lines are the increases of $\log$ numbers of individuals per $g$ weight loss of detritus.
The numbers of Diplolaimella dievengatensis were most clearly related to decomposition rate (Fig. 3A). The regression lines fit well for the experiments carried out in spring, summer and autumn ( $p<0.001)$ but not in winter $(p=0.15)$. In spring, summer and autumn the slopes of the regression lines indicate that 4.6 to 9.6 times more specimens of $D$. dievengatensis occurred with an increased weight loss of $1 \mathrm{~g}$ in $100 \mathrm{~d}$.

Diplolaimelloides bruciei (Fig. 3B) is less frequently found in the mesh containers than Diplolaimella dievengatensis. Only in autumn was this species found in more than $50 \%$ of the containers. In this season the correlation between numbers and decomposition rate was high and the estimated slope of the regression line indicates that 7.9 times more specimens occurred with an increased weight loss of $1 \mathrm{~g}$ in $100 \mathrm{~d}$ (Fig. 3B). In summer $D$. bruciei was completely absent. In spring and winter the occurrence of $D$. bruciei was low, and the calculated regression coefficients were not significantly different from zero.

The numbers of Monhystera parva (Fig. 3C) found in the mesh containers ranged from 0 to more than 40000 specimens per container. Only in treatments with fresh leaves did the numbers significantly exceed the numbers found in control treatments. In some mesh containers, $M$. parva constituted more than $50 \%$ of the total number of nematodes. The high numbers of $M$. parva occurred in winter and spring and not in summer and autumn. The linear regression equations poorly 
describe the relation between the number of specimens and weight losses. Only in spring is the regression coefficient significantly different from zero. In each season, however, the highest numbers were found in the mesh containers with the highest weight losses, i.e. the fresh leaf treatment.

Desmolaimus zeelandicus occurred in almost all samples. The regression coefficients are significantly different from zero in summer and autumn, but not in spring and winter (Fig. 3D). The slopes of the regression lines in summer and autumn were less steep than the slopes found for the species of the family Monhysteridae. From the calculated slopes it can be estimated that in summer and autumn 1.5 to 1.6 more specimens occurred with an increased weight loss of $1 \mathrm{~g}$ in $100 \mathrm{~d}$.

Theristus acer occurred only in spring and in summer in more than $50 \%$ of the containers. In the winter $T$. acer was almost absent. The regression coefficient, fitted for the summer data, is significantly different from zero, and is intermediate between the slopes found for the monhysterids and for Desmolaimus zeelandicus (Fig. 3E). From the regression equation it can be derived that in summer 2.9 times more specimens occurred with an increased weight loss of $1 \mathrm{~g}$ in $100 \mathrm{~d}$. In autumn the slope is also significantly different from zero and is very close to the figure found in summer. However, $T$. acer occurred in only 7 of the 20 mesh containers.

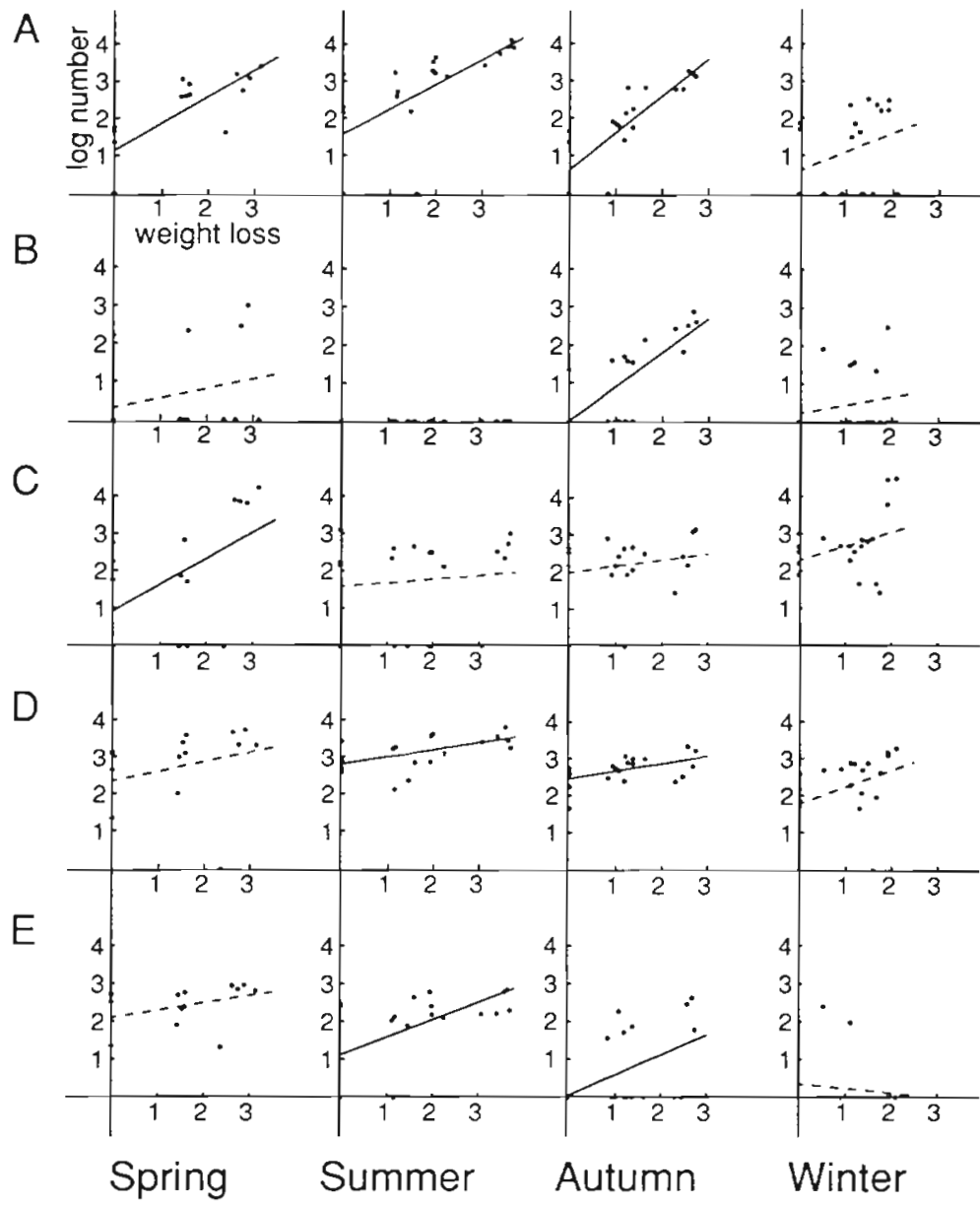

Fig. 3. Plots of the log number of specimens against the decomposition rates (A) Diplolaimella dievengatensis; (B) Diplolaimelloides bruciei; (C) Monhystera parva; (D) Desmolaimus zeelandicus; (E) Theristus acer. Horizontal axis denotes dry weight losses (g per mesh container), vertical axis denotes the log number of nematodes per mesh container. Lines are linear regression lines. Broken lines indicate non-significant regression coefficients

\section{DISCUSSION}

The decomposition rates found in this study ranged from 25 to $85 \%$ weight losses after $100 \mathrm{~d}$ and are in the range found for Spartina spp. in the literature. Montagna \& Ruber (1980) summarized decomposition rates from 6 studies on the decomposition of $S$. alterniflora which covered different seasons. The weight losses after $100 \mathrm{~d}$ in these studies ranged from 25 to $90 \%$, and our data fall within this range. Hemminga \& Buth (1991) reviewed studies on decomposition of salt marsh halophytes in the Netherlands. They calculated mean decomposition rates for $S$. anglica leaves ranging from 0.25 to $0.45 \% \mathrm{~d}^{-1}$ over a period of $6 \mathrm{mo}$ Assuming negative exponential decay, this would result in weight losses of 22 to $36 \%$ after $100 \mathrm{~d}$.
Obviously the wide range in our study is a result of the separation into different quality classes and the influence of different seasons. In the studies reviewed by Hemminga \& Buth (1991) samples of a mixture of quality types were used; other studies were performed in only 1 season.

A wide range of nematode species occurred in the mesh containers. The abundances of most of these species were not correlated with decomposition rate, they occurred in equal densities in treatments with decomposing material and in the control treatments. Apparently, the decomposing material forms only a living space for them. Our observations that the numbers of individuals of these species numerically dominate the total nematode fauna in the litter are consistent with the results of Montagna \& Ruber (1980) and Buth \& de Wolf (1985), who found that the total number 
of nematodes in halophyte litter was dependent on the available space expressed as the amount of litter and not on the age of the decomposing detritus.

The RDA analysis showed that of the many species present in the litter, the number of specimens of only a few species were positively correlated with decomposition rate. These species were found in high numbers in the treatments with the highest decomposition rates, occurred in lower numbers in the treatments with aged leaf material and were practically absent in the control treatments. To date such a direct relation between decomposition rate and nematode numbers has not been found in field experiments. Three of the associated species, Diplolaimella dievengatensis, Diplolaimelloides bruciei and Monhystera parva, are members of the family Monhysteridae. Desmolaimus zeelandicus belongs to the family Linhomoeidae and Theristus acer is a member of the family Xyalidae. Members of the family Monhysteridae are considered non-selective deposit feeders (Wieser 1959) and are always found on locations with high organic inputs (Riemann 1968, Lambshead 1986) or otherwise disturbed locations (Bongers et al. 1991). D. bruciei is mostly found in association with Spartina debris (Warwick 1981, Bouwman et al. 1984). Bouwman et al. (1984) stated that the non-selective feeding behaviour is efficient if the concentration of food (bacteria) is high and not mixed with non-edible particles of the same size. The decomposing Spartina detritus in the mesh containers probably provides high concentrations of bacteria and consequently offers a favourable environment to nonselective deposit feeders. The relation between decomposition rate and the numbers of the 5 above-mentioned species depended on the species and on the season. In winter the numbers of the 5 species did not increase significantly with decomposition rates, but $D$. dievengatensis had significant regression coefficients in spring, summer and autumn, $D$. zeelandicus and $T$. acer in summer and autumn, while $D$. bruciei and $M$. parva increased significantly with decomposition rate in autumn and spring respectively.

The lack of correlation between the abundances of the majority of the nematode species and decomposition rate, as we found in our study, is probably because many of these species feed on microalgae or diatoms or they are omnivorous or carnivorous species, whereas the microbial organisms directly involved in halophyte decomposition are fungi and bacteria (Newell et al. 1989). The positive correlation between the abundance of the 5 microbivorous species and the decomposition rate of Spartina anglica leaves is probably caused by increased microbial biomass production. Higher decomposition rates imply a higher microbial activity and probably also a higher microbial biomass production. This increased availability of food for the microbivorous nematodes allows higher nematode population densities (cf. Findlay 1982).

The populations of microbivorous species of nematodes on halophyte litter may not only react to changing rates of decomposition, they may also, in turn, influence these rates. Several studies showed that in the presence of bacterivorous nematodes of the family Monhysteridae, higher weight losses of detritus occurred (Findlay \& Tenore 1982, Rieper-Kirchner 1989, Alkemade et al. 1992). This stimulatory effect of nematodes probably depends on the population density (Tietjen \& Alongi 1990, Alkemade et al. 1992). If under field conditions nematode species are able to stimulate decomposition of Spartina leaves then the most likely candidates are those whose numbers correlate with decomposition rate, as were identified in our study. Further investigation on the role of nematodes in decomposition processes should be focused on these decomposition-associated species. The most pronounced effects of these nematode species on decomposition rates may be expected on plant material in the first stages of decomposition in the warmer seasons (spring to autumn), since under these circumstances the highest numbers were found. As the time of year in which the correlation between numbers and decomposition rate was found varied between species, it is possible that these species exert their effect on litter decomposition in different seasons.

Acknowledgements. The authors thank Dr P. M. J. Herman for statistical advice, Prof. Dr Ir. A. F. van der Wal for fruitful discussions and critical reading of the manuscript and Dr $M$ Vincx for help with the identification of the nematodes. Communication no. 653 of the Centre for Estuarine and Coastal Ecology.

\section{LITERATURE CITED}

Alkemade, R., Wielemaker, A., Hemminga, M. (1992). Stimulation of decomposition of Spartina anglica leaves by the bacterivorous marine nematode Diplolaimelloides bruciei (Monhysteridae). J. exp. mar Biol. Ecol. 159: $267-278$

Bongers, T., Alkemade, R., Yeates, G. W. (1991). Interpretation of disturbance-induced maturity decrease in marine nematode assemblages by means of the Maturity Index. Mar. Ecol. Prog. Ser. 76: 135-142

Bouwman, L. A. (1983). A survey of nematodes from the Ems estuary. Part II. Species assemblages and associations Zool. Jb. (Abt. Syst. Ökol. Geogr. Tiere) 110: 345-376

Bouwman, L. A., Romeyn, K., Kremer, D. R., van Es, F. B (1984). Occurrence and feeding biology of some nematode species in Aufwuchscommunities. Cah. Biol. mar. 25: $287-303$

Buth, G. J. C., de Wolf, L. (1985). Decomposition of Spartina anglica, Elytrigia pungens and Halimione portulacoides in a Dutch salt marsh in association with faunal and habitat influences. Vegetatio 62:337-335

Findlay, S. E. G. (1982). Effect of detrital nutritional quality on 
population dynamics of a marine nematode (Diplolaimella chitwoodi). Mar. Biol. 68: 223-227

Findlay, S., Tenore, K. R. (1982). Effect of a free-living marine nematode (Diplolaimella chitwoodi) on detrital carbon mineralization. Mar. Ecol. Prog. Ser. 8: 161-166

Fricke, A. H. (1979). Meiofauna extraction efficiency by a modified Oostenbrink apparatus. Helgoländer wiss. Meeresunters. 32: 436-443

Heip, C., Vincx, M., Vranken, G. (1985). The ecology of marine nematodes. Oceanog. mar. Biol. A. Rev. 23: 399-489

Hemminga, M. A., Buth, G. J. C. (1991). Decomposition in salt marsh ecosystems of the S. W. Netherlands: the effects of biotic and abiotic factors. Vegetatio 92: 73-83

Jongman, R. H. G., ter Braak, C. J. F., van Tongeren, O. F. R. (1987). Data analysis in community and landscape ecology. PUDOC, Wageningen

Lambshead, P. J. D. (1986). Sub-catastrophic sewage and industrial waste contamination as revealed by marine nematode faunal analysis. Mar. Ecol. Prog. Ser. 29: 247-260

Montagna, P. A., Ruber, E. (1980). Decomposition of Spartina alterniflora in different seasons and habitats of a Northern Massachusetts salt marsh, and a comparison with other Atlantic regions. Estuaries 3: 61-64

Newell, S. Y., Fallon, R. D., Miller, J. D. (1989). Decomposition and microbial dynamics for standing, naturally positioned leaves of the salt-marsh grass Spartina alterniflora. Mar. Biol. 101: 471-481

Reice, S. E., Stiven, A. E. (1983). Environmental patchiness, litter decomposition and associated faunal patterns in a Spartina alterniflora marsh. Estuar. coast. Shelf Sci. 16: $559-571$

Riemann, F. (1968). Nematoden aus dem Strandanwurf. Veröff. Inst. Meeresforsch. Bremerhaven 11: 25-35

Rieper-Kirchner, M. (1989). Microbial degradation of North

This article was submitted to the editor
Sea macroalgae: filed and laboratory observations Botanica mar. 32: 241-252

's Jacob, J. J., van Bezooijen, J. (1986). Manual for practical work in nematology. Agricultural University, Wageningen

Swift, M. J., Heal, O. W., Anderson, J. M. (1979). Decomposition in terrestrial ecosystems. Blackwell Scientific Publications, Oxford

ter Braak, C. J. F. (1990). CANOCO 3.10. Agricultural Mathematics Group, Wageningen

ter Braak, C. J. F., Prentice, I. C. (1988). A theory of gradient analysis. Adv. ecol. Res. 18: 271-317

Tietjen, J. H., Alongi, D. M. (1990). Population growth and effects of nematodes on nutrient regeneration and bacteria associated with mangrove detritus from northeastern Queensland (Australia). Mar. Ecol. Prog. Ser. 68: 169-179

van der Meer, J. (1990). Exploring macrobenthos-environment relationship by canonical correlation analysis. J. exp. mar. Biol. Ecol. 148: 105-120

Vincx, M. (1986). Free-living marine nematodes from the southern bight of the North Sea. Ph.D. thesis, State University of Ghent, Ghent

Vincx, M. (1989). Seasonal fluctuations and production of nematode communities in the Belgian coastal zone of the North Sea. Verhandelingen van het symposium 'invertebraten van België' State University of Ghent, Ghent, p. $57-66$

Warwick, R. M. (1981). The influence of temperature and salinity on energy partitioning in the marine nematode Diplolaimelloides bruciei. Oecologia 51: 318-325

Wieser, W. (1959). Free-living nematodes. IV. General part. Reports of the Lund University expedition 1948-1949. Acta Univ. lund. (Sect. 2) 55(5): 68-85

Wilkinson, L. (1990). SYSTAT: the system for statistics. SYSTAT, Inc., Evanston, IL

Manuscript first received: February 12, 1993

Revised version accepted: July 2, 1993 